\title{
Contraceptive Use and Its Associated Factors among Women Who Gave Birth within 12 Months in Dubti Town, Pastoral Community, of Afar Region Northeast, Ethiopia
}

\author{
Abdu Yimam $\mathbb{D}^{1},{ }^{1}$ Girmatsion Fisseha, ${ }^{2}$ Mebrahtu Kalayu, ${ }^{2}$ and Etsay Woldu Anbesu $\mathbb{D}^{3}$ \\ ${ }^{1}$ Save the Children, Afar Region, Ethiopia \\ ${ }^{2}$ School of Public Health, College of Health Science, Mekelle University, Tigray, Ethiopia \\ ${ }^{3}$ Department of Public Health, College of Medical and Health Sciences, Samara University, Afar, Ethiopia
}

Correspondence should be addressed to Abdu Yimam; abdgew2004@yahoo.com

Received 28 October 2020; Revised 21 March 2021; Accepted 25 June 2021; Published 7 July 2021

Academic Editor: Kaushik Maiti

Copyright (c) 2021 Abdu Yimam et al. This is an open access article distributed under the Creative Commons Attribution License, which permits unrestricted use, distribution, and reproduction in any medium, provided the original work is properly cited.

\begin{abstract}
Introduction. Substantial numbers of women are not using contraceptives in their postpartum period and die due to avoidable causes related to birth complications. Contraceptives use within 12 months of childbirth has given less attention in Ethiopia. Thus, this study is aimed to assess contraceptive use and its associated factors among women who gave birth within 12 months in Dubti town, pastoral community of Afar region, Ethiopia. Methods. A community-based cross-sectional study was conducted among 342 women in the Dubti town. A systematic random sampling technique was employed to identify and enroll women. Data were collected using a pretested, structured, and interviewer-administered questionnaire. Descriptive statistics were done, and logistic regression analysis was employed to identify the factors associated with contraceptive use. The statistical association was measured by odds ratio with a $95 \%$ confidence interval. $p$ value $<0.05$ was considered as statistically significant. Results. In this study, 103 (30.1\%) [95\% CI: 25.4\%, 35.1\%] women have used contraceptives. Women who had secondary educational level $(\mathrm{AOR}=3.53,95 \% \mathrm{CI}(1.68,7.36)$, had antenatal care follow-up $(\mathrm{AOR}=1.93,95 \% \mathrm{CI}(1.01,3.69)$, and visited by health worker after delivery $(\mathrm{AOR}=2.54,95 \% \mathrm{CI}(1.37,4.68)$ were associated with increased odds of contraceptives use. Conclusions. This study revealed that the prevalence of contraceptive use was low compared to the national recommended figure. Secondary educational level, having antenatal care follow-up, and being visited by health workers after delivery were predictors of contraceptive use. Thus, increase the educational status of women, antenatal care follow-up service, and visiting after delivery by health workers are important interventions to promote the use of contraceptives in the postpartum period.
\end{abstract}

\section{Introduction}

Family planning is a means of promoting the health of mothers, families, and reduce high maternal, infant, and child mortality. Postpartum contraceptive is the prevention of unintended and closely spaced pregnancies during the first 12 months after childbirth [1]. Substantial numbers of women are not using contraceptives in their postpartum period, which leads to a risk of pregnancy [2]. A systematic review and meta-analysis of postpartum contraceptive use among women in low- and middle-income countries indicated that the overall pooled modern contraceptive preva- lence was $41.2 \%$ and the lowest in West Africa (36.3\%). The pooled prevalence of unmet need was $48.5 \%$ and the highest in South Asia/South East Asia (59.4\%) [2]. Ethiopia has the lowest postpartum care coverage of $13 \%$ compared to SubSaharan Africa country, and the Afar region has 6.5\% postpartum care coverage which is the lowest compared to other regions of Ethiopia. Moreover, the national contraceptive coverage is low among currently married women $35 \%$ and, in the Afar region, has the lowest $12 \%$ compared to the national figure [3].

Pregnancies occurring within a year of the mother's previous birth are riskier for the health of both the mother and 
the child, and these increase childhood and maternal mortality $[4,5]$. Contraceptives use can avert more than $30 \%$ of maternal deaths and $10 \%$ of child mortality [6].

Review of literature showed that age of mothers, religion, ethnicity, marital status, birth interval, family size, parental education, parental occupation, household wealth index, ever used contraceptive, the number of children, history of abortion, menses resumed, started sex, planned birth, antenatal care follow-up, place of delivery, postnatal care, knowledge, and attitude on contraceptive use were factors affecting contraceptives use [7-16].

In Ethiopia, though the World Health Organization (WHO) and Ethiopian family planning program recommend an interval of at least 2 years following a live birth $[17,18]$, still fertility is high about 5.8 particularly in pastoral regions [3]. Moreover, though improvement in increased contraceptive utilization coverage and reduction of maternal mortality 412 per 100,000 live birth due to strategies implemented by government and nongovernmental organizations [3], women still die due to avoidable causes related to pregnancy and birth complications. Contraceptives use during postpartum the period has given less attention and no indicator measurement in Ethiopia's health management information system. Thus, this study aimed to assess contraceptive use and its associated factors among women who gave birth within 12 months in Dubti town, pastoral community of Afar region, Northeast Ethiopia in 2018.

\section{Methods}

2.1. Study Setting and Period. Dubti town is located in Dubti district which is one of the eight districts of Zone one. It is $595 \mathrm{~km}$ northeast of Addis Ababa. Dubti town has 1 kebele (the lowest administrative structure of district) which has 38 ketenas (the lowest sub administrative structure of kebele). Based on the 2007 Census population projection, the number of women in the reproductive age in Dubti town was 2586 , and the number of women within the last 12 months of childbirth was 1091. Dubti town has 1 health center and one general hospital.

2.2. Study Design and Population. A community-based crosssectional study was conducted among all systematically selected women who give birth within the last 12 months in Dubti town. The women, who were ill during the study period and were unable to respond, were excluded from the study.

\subsection{Sample Size Determination and Sampling Techniques.} The sample size was determined by using the single population proportion formula with the following assumptions: considering 5\% type one error, 95\% confidence interval (CI), and $29.3 \%$ proportion of contraceptive use within 12 months of childbirth [19]. Then, we added 10\% nonresponse, and the final sample size was 350 participants.

Out of thirty-eight ketenas, 10 ketenas were selected by using the lottery method. The calculated sample size was proportionally allocated to randomly selected ketenas. There was a total of 1091 women delivered within the last 12 months prior to data collection period in the randomly selected ketenas (i.e., Ketena $-2=80$, Ketena $-4=120$, Ketena $-7=95$, Ketena $-9=115$, ktena $-11=106$, ketene $-15=75$, ketene $-22=125$, ketene $-24=121$, Ketena $-30=109$, ketene $32=145$ ). A systematic random sampling technique was employed to enroll the study participants. Accordingly, every three participants were selected by using a systematic random sampling technique till the required sample size has been reached.

2.4. Study Variables. The outcome variable of this study was contraceptive use. It was defined as if mothers used contraceptives to prevent unintended and closely spaced pregnancies within the first 12 months period following birth. It was coded as "1" for "yes" response while "0" for "no" response during analysis.

The independent variables were sociodemographic characteristics (age of mothers, religion, ethnicity, marital status, birth interval, family size, parental education, parental occupation, and household income), reproductive and health services related characteristics (ever used contraceptive, number of children, history of abortion, menses resumed, started sex, planned birth, current pregnancy status, antenatal care follow-up, place of delivery, and postnatal care), and knowledge and attitude on contraceptive use. Good knowledge was measured if mothers scored $75 \%-100 \%$ of the total knowledgerelated questions unless considered as having poor knowledge (scoring of $<75 \%$ ). The attitude of mothers to words contraceptives was measured by asking mothers about their subjective opinion, outlook, position, and ideas towards contraceptive methods. Mothers were classified as having a positive attitude if scored $75-100 \%$ from total attitude questions and considered as having a negative attitude if scored $\leq 75 \%$ attitude questions [16].

2.5. Data Collection Tools and Techniques. Data were collected by using a pretested, structured, and intervieweradministered questionnaire adapted from literature reviews and the Ethiopian Demographic and Health Survey [3]. The adapted questionnaire was modified to fit the local circumstances and the research objective. The questionnaire was prepared first in English and translated into Amharic by an English instructor who is fluent in both languages. The Amharic questioner was used to collect the data. The tool was pretested on 18 women other than the source population in the Samar-logia city administration. The pretest was done to ensure clarity, wordings, logical sequence, and skip patterns of the questions. Then, amendments to the questionnaire were made accordingly. The data were collected by six preparatory completed students and supervised by two diploma nurses. The supervisors checked the day-today activities of data collectors regarding the completion of questionnaires, clarity, and proper coding of the responses.

2.6. Data Quality Control. Students who can speak the local language were recruited as data collectors. The data collectors and the supervisors were trained for one and half days by the principal investigator on the study tool, objective, consent form, and data collection procedure. 
TABLE 1: Sociodemographic characteristics of the study participants in Dubti town, pastoral community, Afar region, Northeast Ethiopia, May 2018.

\begin{tabular}{|c|c|c|c|}
\hline Variables & Category & Frequency $(N)$ & Percentage $(\%)$ \\
\hline \multirow{3}{*}{ Age of mothers in years } & $>19$ & 24 & 7 \\
\hline & $20-34$ & 213 & 62.3 \\
\hline & $>34$ & 105 & 30.7 \\
\hline Mean age $( \pm S D)$ & $29.82( \pm 7.45)$ & & \\
\hline \multirow{3}{*}{ Birth interval in month } & No previous birth & 48 & 14 \\
\hline & $<24$ months & 175 & 51.2 \\
\hline & $\geq 24$ months & 119 & 34.8 \\
\hline \multirow{3}{*}{ Religion } & Muslim & 236 & 69 \\
\hline & Orthodox & 84 & 24.6 \\
\hline & Protestant & 22 & 6.4 \\
\hline \multirow{4}{*}{ Ethnicity } & Afar & 156 & 45.6 \\
\hline & Amhara & 124 & 36.3 \\
\hline & Tigray & 49 & 14.3 \\
\hline & Others (Wolayta, Oromo) & 13 & 3.8 \\
\hline \multirow{3}{*}{ Marital status } & Married & 286 & 83.6 \\
\hline & Divorced & 29 & 8.5 \\
\hline & Single & 27 & 7.9 \\
\hline \multirow{4}{*}{ Maternal education } & No education & 106 & 31 \\
\hline & Primary & 124 & 36.3 \\
\hline & Secondary & 74 & 21.6 \\
\hline & Higher & 38 & 11.1 \\
\hline \multirow{6}{*}{ Maternal occupation } & Housewife & 38 & 11.1 \\
\hline & Pastoral & 138 & 40.4 \\
\hline & Daily labor & 36 & 10.5 \\
\hline & Government & 69 & 20.2 \\
\hline & Small trade & 38 & 11.1 \\
\hline & Students & 23 & 6.7 \\
\hline \multirow{5}{*}{ Husband occupation } & Farmer & 27 & 9.5 \\
\hline & Pastoral & 105 & 36.7 \\
\hline & Daily labor & 43 & 15 \\
\hline & Merchant & 55 & 19.2 \\
\hline & Government & 56 & 19.6 \\
\hline \multirow{4}{*}{ Husband education } & No education & 40 & 14 \\
\hline & Primary & 82 & 28.7 \\
\hline & Secondary & 109 & 38.1 \\
\hline & Higher & 55 & 19.2 \\
\hline \multirow{4}{*}{ Family size } & $\leq 2$ & 74 & 21.6 \\
\hline & $3-4$ & 108 & 31.6 \\
\hline & $5-6$ & 78 & 22.8 \\
\hline & $>6$ & 82 & 24 \\
\hline \multirow{3}{*}{ Household monthly income (ETBr) } & $\leq 500$ & 61 & 17.8 \\
\hline & $501-1000$ & 69 & 20.2 \\
\hline & $>1000$ & 212 & 62 \\
\hline
\end{tabular}


TABLE 2: Reproductive and health services characteristics of the study participants in Dubti town, pastoral community, Afar region, Northeast Ethiopia, May 2018.

\begin{tabular}{|c|c|c|c|}
\hline Variables & Category & Frequency $(N)$ & Percentage (\%) \\
\hline \multirow{3}{*}{ Number of children } & 1 & 48 & 14 \\
\hline & $2-3$ & 170 & 49.7 \\
\hline & $>3$ & 124 & 36.3 \\
\hline \multirow{2}{*}{ History of abortion } & Yes & 71 & 20.8 \\
\hline & No & 271 & 79.2 \\
\hline \multirow{2}{*}{ Number of abortion } & 1 & 50 & 70.4 \\
\hline & $2-3$ & 21 & 29.6 \\
\hline \multirow{2}{*}{ Menses resumed after the last delivery } & Yes & 287 & 83.9 \\
\hline & No & 55 & 16.1 \\
\hline \multirow{2}{*}{ Started sex after the last delivery } & Yes & 299 & 87.4 \\
\hline & No & 43 & 12.6 \\
\hline \multirow{2}{*}{ Birth planned } & Yes & 207 & 60.5 \\
\hline & No & 135 & 39.5 \\
\hline \multirow{2}{*}{ Ever used contraceptive } & Yes & 117 & 34.2 \\
\hline & No & 225 & 65.8 \\
\hline \multirow{2}{*}{ Currently using contraceptive } & Yes & 103 & 30.1 \\
\hline & No & 239 & 69.9 \\
\hline \multirow{3}{*}{ Types of contraceptive } & Pills & 29 & 28.5 \\
\hline & Injectable & 68 & 66 \\
\hline & Implant & 6 & 5.8 \\
\hline \multirow{2}{*}{ Source of the services } & Government & 33 & 32.1 \\
\hline & Private & 70 & 67.9 \\
\hline \multirow{2}{*}{ Intension to use contraceptive in the future } & Yes & 157 & 65.7 \\
\hline & No & 82 & 34.7 \\
\hline \multirow{5}{*}{ Reason not to use contraceptives } & Lack of knowledge & 12 & 5 \\
\hline & Infrequent sex & 15 & 6.3 \\
\hline & Opposition to use & 24 & 10 \\
\hline & Side effect & 34 & 14.2 \\
\hline & Exclusive breastfeeding & 154 & 64.4 \\
\hline \multirow{2}{*}{ Currently pregnant } & Yes & 25 & 7.3 \\
\hline & No & 317 & 92.7 \\
\hline \multirow{2}{*}{ Had ANC follow-up } & Yes & 233 & 68.1 \\
\hline & No & 109 & 31.9 \\
\hline \multirow{2}{*}{ Number of ANC visits } & $1-3$ & 168 & 72.1 \\
\hline & $\geq 4$ & 65 & 27.9 \\
\hline \multirow{2}{*}{ Place of delivery } & Home & 135 & 39.5 \\
\hline & Health facility & 207 & 60.5 \\
\hline \multirow{2}{*}{ Visited by health worker after delivery } & Yes & 82 & 24 \\
\hline & No & 260 & 76 \\
\hline
\end{tabular}

2.7. Data Management and Analysis. The data were checked for completeness, coded, and entered into the Epi info software, and exported to SPSS version 20 for analysis. The descriptive analysis was done, and the results were presented using texts, frequency tables, figures, and mean with standard deviation.

A binary logistic regression analysis was done to assess the association between the outcome variable with each 
TABLE 3: Knowledge and attitude of the study participants on contraceptive use in Dubti town, pastoral community, Afar region, Northeast Ethiopia, May 2018.

\begin{tabular}{|c|c|c|c|}
\hline Variables & Category & Frequency $(N)$ & Percentage $(\%)$ \\
\hline Mentioned methods of contraceptives & Yes & 322 & 94.2 \\
\hline Used after delivery & No & 20 & 5.8 \\
\hline \multirow{6}{*}{ Types of contraceptives ever know (multiple responses) } & Pills & 321 & 99.7 \\
\hline & Injectable & 263 & 81.7 \\
\hline & IUCD & 258 & 80.1 \\
\hline & Implant & 257 & 79.8 \\
\hline & Emergency & 203 & 63 \\
\hline & Others (condom) & 156 & 48.4 \\
\hline \multirow{2}{*}{ Had information on contraceptives } & Yes & 295 & 91.6 \\
\hline & No & 27 & 8.4 \\
\hline \multirow{4}{*}{ Source of information (multiple responses) } & Health workers & 275 & 85.4 \\
\hline & Radio & 115 & 35.7 \\
\hline & TV & 161 & 50 \\
\hline & Friends & 186 & 57.8 \\
\hline \multirow{2}{*}{ Discussed contraceptive methods with husband } & Yes & 110 & 38.5 \\
\hline & No & 176 & 61.5 \\
\hline \multirow{2}{*}{ Husband's attitude on contraceptives } & Favorable & 79 & 71.8 \\
\hline & Unfavorable & 31 & 28.2 \\
\hline \multirow{2}{*}{ Perceived use of contraceptives } & Yes & 329 & 96.2 \\
\hline & No & 13 & 3.8 \\
\hline
\end{tabular}

explanatory variable. Independent variables with a $p$ value less than 0.25 in the bivariable logistic regression analysis were considered for the final model. Correlation between independent variables was assessed but we did not find any correlation. Finally, multivariable logistic regression analysis was done to control potential confounders and to identify the factors associated with the outcome variable. A statistical significance level was declared at a $p$ value of less than 0.05 .

2.8. Ethical Consideration. The study was approved by the Samara University Research and Ethical Review Committee (RERC) on 18, November 2017, with RE ERC 0029/2017. An official letter was written from the Samara University to Dubti District Administration Office. Then, permission and support letter was written by Dubti urban kebele. The women enrolled in the study were informed about the study objectives, benefits, and risks associated with it. Verbal consent was taken from the women before the interview. Confidentiality of responses was maintained throughout the study. For teenagers <, 18 years consent form was signed by their husbands.

\section{Result and Discussion}

3.1. Sociodemographic Characteristics of Participants. In this study, a total of 342 women have included the study with a response rate of $97.8 \%$. The mean age of women was 29.82 years (with a standard deviation of \pm 7.45 ) and about 213
(62.3\%) of the mothers were in the age group of 21-34 years. 236 (69\%) women were Muslim, and 156 (45.6\%) were Afar in the Ethnic. About 106 (31\%) were illiterate, and 175 $(51.2 \%)$ women gave their last birth within birth interval $<24$ months (Table 1).

3.2. Reproductive and Health Services Related Characteristics. In this study, 117 (34.2\%) women have ever used contraceptives, 135 (39.5\%) had no planned birth, 233 (68.1\%) had ANC follow-up, 25 (7.3\%) were pregnant, 135 (39.5\%) delivered at home, and $82(24 \%)$ were visited by health workers after delivery. 103 (30.1\%) [95\% CI: 25.4\%, 35.1\%] women have used contraceptives. Of this, $68(66 \%)$ of them used injectable. 70 $(67.9 \%)$ women have used contraceptives from private health facilities. The main perceived reason not to use contraceptives was exclusive breastfeeding 154 (64.4\%) (Table 2).

3.3. Knowledge and Attitude of the Study Participants on Contraceptive Use. In this study, 322 (94.2\%) women have mentioned the methods of contraceptives, and 275 (85.4\%) reported that the sources of information were received from health workers. 329 (96.2\%) perceived the use of contraceptives, $110(38.5 \%)$ discussed on contraceptive methods with their husbands, and $79(71.8 \%)$ husbands had a favorable attitude on contraceptives (Table 3 ).

3.4. Factors Associated with Contraceptive Use. The selected variables were tested for their contribution to contraceptive utilization using binary logistic analysis. The variables that 
TABLE 4: Binary and multivariable logistic regression analysis showing factors associated with contraceptive use among study participants in Dubti town, pastoral community, Afar region, Northeast Ethiopia, May 2018.

\begin{tabular}{|c|c|c|c|c|c|}
\hline \multirow{2}{*}{ Variables } & \multirow{2}{*}{ Category } & \multicolumn{2}{|c|}{ Contraceptive use } & \multirow{2}{*}{ COR 95\% CI } & \multirow{2}{*}{ AOR 95\% CI } \\
\hline & & Yes, $n(\%)$ & No, $n(\%)$ & & \\
\hline \multirow{4}{*}{ Maternal education } & No education & $20(19.5)$ & $86(36)$ & 1 & 1 \\
\hline & Primary & $33(32)$ & $91(38)$ & $1.56(0.83,8.37)$ & $1.1(0.53,2.14)$ \\
\hline & Secondary & $37(35.9)$ & $37(15.5)$ & $4.3(2.21,8.37)$ & $3.53(1.68,7.36)^{*}$ \\
\hline & Higher & $13(12.6)$ & $25(10.5)$ & $2.24(0.97,5.12)$ & $1.42(0.57,3.53)$ \\
\hline \multirow{2}{*}{ History of abortion } & Yes & $26(25.2)$ & $45(18.8)$ & $1.46(0.84,2.52)$ & $1.35(0.67,2.73)$ \\
\hline & No & $77(74.8)$ & $194(81.2)$ & 1 & 1 \\
\hline \multirow{2}{*}{ ANC follow-up } & Yes & $86(83.5)$ & $147(61.5)$ & $3.17(1.76,5.7)$ & $1.93(1.01,3.69)^{*}$ \\
\hline & No & $17.6(16.5)$ & $92(38.5)$ & 1 & 1 \\
\hline \multirow{2}{*}{ Place of delivery } & Home & $31(30.1)$ & $104(43.5)$ & 1 & 1 \\
\hline & Health facilities & $72(69.9)$ & $135(56.5)$ & $1.78(1.09,2.93)$ & $1.24(0.7,2.2)$ \\
\hline \multirow{2}{*}{ Menses resumed } & Yes & $93(90.3)$ & $194(81.2)$ & $2.16(1.04,4.46)$ & $2.2(0.91,5.32)$ \\
\hline & No & $10(9.7)$ & $45(18.8)$ & 1 & 1 \\
\hline \multirow{2}{*}{ Visited by health worker after delivery } & Yes & $40(38.8)$ & $42(17.6)$ & $2.98(1.77,4.99)$ & $2.54(1.37,4.68)^{*}$ \\
\hline & No & $63(61.2)$ & $197(82.4)$ & 1 & 1 \\
\hline \multirow{2}{*}{ Ever used contraceptives } & Yes & $40(38.8)$ & $77(32.2)$ & $1.34(0.83,2.26)$ & $1.76(0.99,3.11)$ \\
\hline & No & $63(61.2)$ & $162(67.8)$ & 1 & 1 \\
\hline \multirow{2}{*}{ Had information on contraceptives } & Yes & $92(95.8)$ & $203(89.8)$ & $2.61(0.87,7.75)$ & $1.76(0.52 .5 .91)$ \\
\hline & No & $4(4.2)$ & $23(10.2)$ & 1 & 1 \\
\hline
\end{tabular}

*significant at $p<0.05$.

showed associations were being secondary educational level, had ANC follow-up services, delivered at a health facility, resumed menses after last delivery, and visited by health worker after delivery. Then, these variables were entered together to determine their effect on the outcome variable on multivariable logistic regression analysis. Accordingly, secondary educational 1 level $(\mathrm{AOR}=3.53,95 \% \mathrm{CI}(1.68$, 7.36), having ANC follow up services $(\mathrm{AOR}=1.93,95 \% \mathrm{CI}$ $(1.01,3.69)$ and being visited by health worker after delivery (AOR $=2.54,95 \%$ CI $(1.37,4.68)$, were factors statistical associated with postpartum contraceptives use (Table 4).

In this study, the odds of contraceptive use within 12 months of childbirth among women who had a secondary educational level were 3.53 times more compared to women who had no educational level $(\mathrm{AOR}=3.53,95 \%$ CI $(1.68$, 7.36). Women who had antenatal care follow-up were $93 \%$ more likely to contraceptive use within 12 months of childbirth than their counterparts $(\mathrm{AOR}=1.93,95 \%$ CI $(1.01$, 3.69). The odds of contraceptive use within 12 months of childbirth among women who were visited by health workers after delivery were 2.54 times more compared to their counterparts $(\mathrm{AOR}=2.54,95 \% \mathrm{CI}(1.37,4.68)$ (Table 4$)$.

\section{Discussion}

This study was aimed to assess contraceptive use and its associated factors among women who gave birth within 12 months. Based on this, we found that the prevalence of contraceptives use was $30.1 \%$ (95\% CI, 25.4 to 35.1 ).
The prevalence of this study was higher than the study done in Kebrebeya, Somali region, Ethiopia region, $12.3 \%$ [12], Debat district, Northwest Ethiopia, 10.3\% [11]. However, the finding of this study was lower than study conducted in rural Tigray, Ethiopia, 38.3\% [20]; Tigray Axum, Ethiopia, 48\% [21]; Gonder, 48.4\% [7]; Kenya, 49\% [22]; Nigerian, 65.6\% [23]; Malawi, 75\% [8]; and Turkey, 73.7\% [24]. This variation might be due to differences in sociodemographic, cultural, and religious, health service accessibility, awareness, and quality differences for the uptake of contraceptive use. Moreover, it might be also due to the temporal difference in the study periods.

In this study, the odds of contraceptive use within 12 months of childbirth among women who had a secondary educational level were 3.53 times more compared to women who had no educational level $(\mathrm{AOR}=3.53$, 95\% CI (1.68, 7.36). This is consistent with a study conducted in Kebribeyah, Ethiopia Somali region [12], Uganda [13], Malawi [8], other settings of developing countries [6], and the USA [9]. This might be because women's attainment of educational level benefits to a better understanding of the available methods of contraceptives during 12 months of childbirth. Besides, educations increase the level of awareness on contraceptives use and to utilize the method of contraceptives. It has been noted that women's education is an important determinant factor for increasing contraceptive use within 12 months of childbirth [13].

Women who had antenatal care follow-up were 93\% more likely to contraceptive use within 12 months of 
childbirth than their counterparts $(\mathrm{AOR}=1.93,95 \% \mathrm{CI}$ $(1.01,3.69)$. This is consistent with the study done in Kebribeyah, Somali region, Ethiopia [12]; Gonder town, Northwest Ethiopia [7]; Kenya and Zambia [10]; and the United States [15]. This might be the fact that women who attend antenatal care are more likely to get information on contraceptive use. Moreover, women who had frequent visits during ANC had more exposure to counseling and awareness on birth spacing. A previous study showed that providing education on contraceptive use during antenatal care follow-up had Positive results and women that do not attend ANC are at risk of having closely spaced pregnancies and births [9].

The odds of contraceptive use within 12 months of childbirth among women who were visited by health workers after delivery were 2.54 times more compared to their counterparts $(\mathrm{AOR}=2.54,95 \% \mathrm{CI}(1.37,4.68)$ (Table 4$)$. This finding is in line with the study conducted in Kebribeyah, Somali, Ethiopia [12]; Gondar, Ethiopia [7]; Tigray Ethiopia [20]; and United States $[15,16]$. This might be the fact that women visited by health workers after delivery can get postnatal care and counseling service on contraceptive use. It has been noted that postpartum educational and counseling services were a significant contribution to contraceptive use within 12 months of childbirth $[25,26]$.

4.1. Strength and Limitation of This Study. The strength of the study was being community-based, and it can represent the source population. However, the study might have a limitation like respondents' recall bias, and as it is, a crosssectional study design no causal inferences can be made.

\section{Conclusion}

This study revealed that the prevalence of contraceptive use among women who gave birth within 12 months was low compared to the national figure. A secondary educational level, having antenatal care follow-up, and being visited by health workers after delivery were predictors of contraceptive use. Thus, increasing the educational status of women, antenatal care follow-up service, and the visit after delivery by health workers are the important interventions to promote the use of contraceptives in the postpartum period.

\section{Data Availability}

The datasets supporting the conclusions of the study are included in the article, and the datasets used for analysis during the current study are available from the corresponding author on reasonable request.

\section{Disclosure}

The funder had no role in the manuscript writing, editing, approval, or decision to publish.

\section{Conflicts of Interest}

The authors declare that they have no competing interests.

\section{Acknowledgments}

Many thanks go to the Dubti district health administration bureau for providing us a consent letter. We would also like to acknowledge the study subjects, data collectors, and supervisors.

\section{References}

[1] World Health Organization, Programming Strategies for Postpartum Family Planning, WHO, 2013.

[2] R. Dev, P. Kohler, M. Feder, J. A. Unger, N. F. Woods, and A. L. Drake, "A systematic review and meta-analysis of postpartum contraceptive use among women in low-and middleincome countries," Reproductive Health, vol. 16, no. 1, pp. 117, 2019.

[3] FMOH, Central Statistical Agency, ETHIOPIA Demographic and Health Survey, 2016, 2016.

[4] S. O. Rutstein, "Effects of preceding birth intervals on neonatal, infant and under-five years mortality and nutritional status in developing countries: evidence from the demographic and health surveys," International Journal of Gynecology \& Obstetrics, vol. 89, pp. S7-S24, 2005.

[5] A UNFPA, "Decade of change in contraceptive use in Ethiopia," Depth Analysis of the EDHS 2000-2011, 2012.

[6] W. Winfrey and K. Rakesh, Use of family planning in the postpartum period, ICF International, 2014.

[7] Y. Abera, Z. B. Mengesha, and G. A. Tessema, "Postpartum contraceptive use in Gondar town, Northwest Ethiopia: a community based cross-sectional study," BMC Women's Health, vol. 15, no. 1, pp. 1-8, 2015.

[8] C. Bwazi, A. Maluwa, A. Chimwaza, and M. Pindani, "Utilization of postpartum family planning services between six and twelve months of delivery at Ntchisi District Hospital, Malawi," Health, vol. 6, no. 14, 2014.

[9] K. Coleman-Minahan, A. R. Aiken, and J. E. Potter, "Prevalence and predictors of prenatal and postpartum contraceptive counseling in two Texas cities," Women's Health Issues, vol. 27, no. 6, pp. 707-714, 2017.

[10] D. Mai and H. David, "Relationship between Antinatal and postnatal care and post partum modern contraceptive method," BMC Health Services Research, vol. 13, p. 6, 2013.

[11] Z. B. Mengesha, A. G. Worku, and S. A. Feleke, "Contraceptive adoption in the extended postpartum period is low in Northwest Ethiopia," BMC Pregnancy and Childbirth, vol. 15, no. 1, pp. 1-6, 2015.

[12] A. Nigussie, D. Girma, and G. Tura, "Postpartum family planning utilization and associated factors among women who gave birth in the past 12 months, Kebribeyah Town, Somali Region, Eastern Ethiopia," Journal of Women's Health Care, vol. 5, no. 6, 2016.

[13] G. Rutaremwa, A. Kabagenyi, S. O. Wandera, T. Jhamba, E. Akiror, and H. L. Nviiri, "Predictors of modern contraceptive use during the postpartum period among women in Uganda: a population-based cross sectional study," BMC Public Health, vol. 15, no. 1, 2015.

[14] M. P. Sebastian, M. E. Khan, K. Kumari, and R. Idnani, "Increasing postpartum contraception in rural India: evaluation of a community-based behavior change communication intervention," International Perspectives on Sexual and Reproductive Health, vol. 38, no. 2, pp. 068-077, 2012. 
[15] E. K. Wilson, C. I. Fowler, and H. P. Koo, "Postpartum contraceptive use among adolescent mothers in seven states," Journal of Adolescent Health, vol. 52, no. 3, pp. 278-283, 2013.

[16] L. B. Zapata, S. Murtaza, M. K. Whiteman et al., "Contraceptive counseling and postpartum contraceptive use," American Journal of Obstetrics And Gynecology, vol. 212, no. 2, pp. 171. e1-171.e8, 2015.

[17] J. DaVanzo, L. Hale, A. Razzaque, and M. Rahman, "Effects of interpregnancy interval and outcome of the preceding pregnancy on pregnancy outcomes in Matlab, Bangladesh," BJOG: An International Journal of Obstetrics \& Gynaecology, vol. 114, no. 9, pp. 1079-1087, 2007.

[18] A. Kesetebirhan, National Guideline for Family Planning Services in Ethiopia, Federal Democratic Republic of Ethiopia, Ministry of Health, 2011.

[19] A. Gebremariam and H. Gebremariam, "Contraceptive use among lactating women in Ganta-Afeshum District, Eastern Tigray, Northern Ethiopia, 2015: a cross sectional study," BMC Pregnancy and Childbirth, vol. 17, no. 1, p. 421, 2017.

[20] T. H. Abraha, B. B. Gebrezgiabher, B. G. Aregawi, D. S. Belay, L. T. Tikue, and G. M. Welay, "Predictors of postpartum contraceptive use in rural Tigray region, northern Ethiopia: a multilevel analysis," BMC Public Health, vol. 18, no. 1, p. 1017, 2018.

[21] T. H. Abraha, A. S. Teferra, and A. A. Gelagay, "Postpartum Modern Contraceptive Use and Associated Factors in Northern Ethiopia," Epidemiology and Health, vol. 39, 2017.

[22] J. Mumah, K. Machiyama, M. Mutua, C. Mukiira, C. W. Kabiru, and J. C. Cleland, Contraceptive Use and Discontinuation among Postpartum Women in Nairobi Urban Slums, Population Council, 2014.

[23] Z. Iliyasu, H. S. Galadanci, K. M. Danlami, H. M. Salihu, and M. H. Aliyu, "Correlates of postpartum sexual activity and contraceptive use in Kano, northern Nigeria," African Journal of Reproductive Health, vol. 22, no. 1, pp. 103-112, 2018.

[24] S. Kiykac Altinbas, Y. Bayoglu Tekin, B. Dilbaz, S. Kilic, S. S. Khalil, and O. Kandemir, "Impact of having a high-risk pregnancy on future postpartum contraceptive method choice," Women and Birth, vol. 27, no. 4, pp. 254-258, 2014.

[25] J. H. Tang, R. C. Dominik, M. L. Zerden, S. B. Verbiest, S. C. Brody, and G. S. Stuart, "Effect of an educational script on postpartum contraceptive use: a randomized controlled trial," Contraception, vol. 90, no. 2, pp. 162-167, 2014.

[26] K. Kaewkiattikun, "Effects of immediate postpartum contraceptive counseling on long-acting reversible contraceptive use in adolescents," Adolescent Health, Medicine and Therapeutics, vol. Volume 8, pp. 115-123, 2017. 